\title{
MY FOOLISH HEART ESTÁ PARTIDO: ACOMODANDO EXPRESSÕES METAFÓRICAS CONVENCIONAIS COM AS PALAVRAS HEART E CORAÇÃO EM CANÇÕES COUNTRY E SERTANEJAS
}

\section{My foolish heart is broken: accommodating conventional metaphorical expressions} with the word heart in American and Brazilian country songs

RESUMO: Este artigo apresenta o resultado de uma pesquisa sobre expressões metafóricas convencionais em canções sertanejas em português brasileiro e country no inglês americano. O objetivo principal era verificar a ocorrência de expressões metafóricas convencionais com a palavra coração no português brasileiro e com a palavra heart no inglês americano e acomodá-las dentro de metáforas conceituais já reveladas, em particular no estudo de Divardin (2000). O corpus da pesquisa incluiu 15 letras de canções sertanejas e 15 letras de canções country selecionadas a partir das palavras coração e heart. O referencial teórico que serviu de suporte para a análise foi a teoria conceitual de Lakoff e Johnson (1980) e do estudo de Divardin (2000). A análise demonstrou que a maioria das expressões metafóricas coletadas foram geradas a partir das metáforas conceituais THE HEART IS THE PERSON (O CORAÇÃO É A PESSOA) e EMOTIONAL DISTRESS IS PAIN INFLICTED TO THE HEART (ANGÚSTIA EMOCIONAL É DOR IMPOSTA AO CORAÇÃO)2 ${ }^{2}$. Estudos desta natureza são importantes, pois demonstram a importância da linguagem para termos acesso às metáforas conceituais que nos ajudam a revelar o modo através do qual percebemos e entendemos o mundo a nossa volta. As metáforas, anteriormente vistas meramente como um artifício literário, ganham o status de uma importante ferramenta para acessarmos nosso sistema conceitual.

PALAVRAS-CHAVE: Metáforas conceituais; Heart/Coração; Canções country; Canções sertanejas.

ABSTRACT: This article presents the result of a study about the use of conventional metaphorical expressions in country songs. The main goal was to verify the occurrence of metaphorical conventional expressions with the word heart in Brazilian Portuguese and in American English accommodate them within conceptual metaphors revealed mainly in the study by Divardin (2000). The corpus of the research included 15 lyrics of Brazilian country songs and 15 lyrics of American English country lyrics. The theoretical framework that supported the data analysis was the conceptual theory of Lakoff and Johnson (1980) and on the study by Divardin (2000). The analysis demonstrated that most of the metaphorical expressions analyzed are instances of the conceptual metaphors THE HEART IS THE PERSON AND EMOTIONAL DISTRESS IS PAIN INFLICTED TO

\footnotetext{
${ }^{1}$ Doutora em Letras (UFPR) e docente da Universidade Estadual de Ponta Grossa (UEPG). thaisa_de_andrade@hotmail.com

${ }^{2}$ Todas as metáforas são apresentadas em letras maiúsculas de acordo com a convenção nos estudos sobre metáforas (Lakoff e Johnson, 1980).
} 
THE HEART. Studies like this are important as they demonstrate the importance of language to access the conceptual metaphors that help us reveal how we perceive and understand the world around us. Thus, metaphors, which in the past were seen as mere literary artifacts, gain the status of an important tool to access our conceptual system.

KEYWORDS: Conceptual metaphors; Heart/Coração; Country songs; Sertaneja songs.

\section{INTRODUÇÃO}

O reconhecimento e o uso de expressões idiomáticas por falantes de uma língua, seja ela materna ou estrangeira, demonstram em grande parte o seu nível de fluência, pois o uso de expressões, gírias e provérbios, por exemplo, dão "colorido" à língua. Reconhecer e usar expressões idiomáticas e metáforas também contribui para o sucesso comunicativo entre falantes/estudantes de línguas (Lima, 2009). Além disso, o uso de expressões idiomáticas e de metáforas chama a atenção não apenas ao conteúdo da mensagem mas também estimulam a reflexão sobre a linguagem utilizada.

Os estudos sobre metáforas, interesse principal deste artigo, datam da época de Aristóteles, mas foi apenas no século passado que elas foram consideradas como uma parte significativa das línguas. Em particular nas décadas de 1970 e 1980, estudiosos com Searle (1979) e Lakoff e Johnson (1980) se interessaram no processamento de informações que contribuíram para o desenvolvimento de teorias proporcionando uma visão cognitiva e interdisciplinar sobre as metáforas, que passaram a ser entendidas como um modo de raciocínio e não apenas como um instrumento estilístico usado para "enfeitar" o discurso.

De acordo com Hoffman (1983), falantes de língua inglesa, por exemplo, produzem cerca de 3.000 novas metáforas convencionais por semana. Os números mencionados em outras pesquisas são bastante expressivos e reforçam a ideia de que, se as pessoas fossem limitadas ao discurso literal, o processo de comunicação seria grandemente prejudicado (Bowles, 1995).

A compreensão pelos usuários de línguas, tanto materna quanto estrangeira, de que há um sistema conceitual organizado subjacente às expressões metafóricas (Lakoff e Johnson, 1980) contribui para o entendimento dos diversos discursos do dia a dia. Isso acontece porque muitas expressões metafóricas podem conter elementos presentes na memória dos usuários das línguas que possibilitam a incorporação a outros, compartilhados por diversas culturas. 
No entanto, o uso de expressões metafóricas nem sempre foi considerado como um sistema conceitual organizado usado para expressar nossa compreensão e experiências no mundo. As expressões metafóricas já foram entendidas apenas como "expressões linguísticas elaboradas, rebuscadas que resultam de um processo consciente e criativo" (Divardin, 2002, p. 74) e utilizadas como um "artifício literário" (Coimbra et al, 2011, p. 548).

Os estudos de Lakoff e Johnson publicados na obra Metaphors We live By (1980) mostram como no campo da linguística cognitiva as metáforas são instrumentos que nos permitem "entender e experimentar uma determinada coisa em termos de outra" (Lakoff e Johnson, 1980, p. 5). Em outras palavras, as expressões têm funções cognitivas que estruturam nossas experiências. No entanto, é importante lembrar a distinção entre metáforas linguísticas e metáforas conceituais. Lakoff e Johnson afirmam que usamos as metáforas linguísticas para termos acesso às conceituais, ou seja, àquelas metáforas que estão na nossa mente e que não percebemos. As expressões linguísticas utilizadas, ou seja, as expressões convencionais idiomáticas ou não, dão pistas sobre a nossa maneira de pensar, e esse pensamento pode constituir uma metáfora conceitual. Tomemos, por exemplo, algumas sentenças que já são comumente usadas pelas pessoas ao discutirem o exame do vestibular: "Neste curso o aluno tem um período de tempo maior para se preparar para o vestibular; O curso extensivo é o início de uma nova fase para a conquista do curso superior; O dia do exame é um dos mais esperados para quem está batalhando por uma vaga na universidade; Para o vestibular é muito importante ter o domínio de certas estratégias para controlar o tempo". Um olhar mais atento para as palavras preparar, conquista, batalhando, domínio e estratégias nas sentenças acima nos fazem perceber que são palavras que usamos para falar sobre guerra. Dessa forma, podemos afirmar a existência da metáfora conceitual O VESTIBULAR É UMA GUERRA (Divardin, 2000).

É importante destacar que o presente estudo contribui para os estudos sobre o reconhecimento, a produtividade e o uso de metáforas convencionais no dia a dia, pois explora o uso de metáforas no inglês e no português, respectivamente, em canções country e sertanejas (estilos musicais românticos que tratam da vida cotidiana e que geraram a hipótese de que a ocorrência das metáforas escolhidas para o estudo seria elevada) fontes não foram exploradas por Divardin (2000). Ou seja, o estudo demonstra como as metáforas conceituais estão presentes nos mais variados contextos. O interesse em 
desenvolver um estudo comparando a produtividade das metáforas em inglês e português está relacionado com o meu contexto profissional de atuação, a saber, o ensino de língua inglesa para brasileiros.

\section{METODOLOGIA}

O presente estudo foi desenvolvido na forma de uma pesquisa bibliográfica (Bortoni-Ricardo, 2008) baseado no estudo de Divardin (2000) que demonstrou que as metáforas conceituais THE HEART IS THE PERSON e EMOTIONAL DISTRESS IS PAIN INFLICTED TO THE HEART foram as mais produtivas nas seguintes fontes: dicionários monolíngues e bilíngues, dicionários de expressões idiomáticas, provérbios, gírias, clichés e colocações, além de jornais e revistas. Já este estudo concentra-se apenas em canções country na língua inglesa e sertanejas no Português.

No estudo de Divardin, a metáfora conceitual THE HEART IS THE PERSON foi a mais produtiva com 41 exemplos no inglês americano e 35 no português brasileiro, e EMOTIONAL DISTRESS IS PAIN INFLICTED TO THE HEART teve ocorrência em 32 exemplos no inglês americano e 25 no português brasileiro.

A ideia inicial era selecionar para o corpus da presente pesquisa letras de canções country e sertaneja que receberam os prêmios Grammy e Grammy Latino nos anos de 2014 e 2015 e cujos títulos apresentassem as palavras heart e coração. A definição por estes estilos musicais está relacionada ao fato de que estes estilos tratam da vida cotidiana e são românticas, daí a hipótese da ocorrência das metáforas com as palavras heart e coração.

No entanto, a coleta inicial não resultou em títulos de canções com as palavras heart e coração. Assim, o corpus da pesquisa incluiu a seleção em sítios de busca especializados em letras de canções. Desta forma, a seleção das $30^{3}$ canções foi aleatória a partir dos 30 primeiros títulos encontrados com as palavras heart e coração, 15 em inglês americano e 15 em português do Brasil, respectivamente nos meses de março e abril de 2016.

As letras das músicas foram analisadas tendo como referencial teórico a teoria conceitual de Lakoff e Johnson (1980) e o estudo de Divardin (2000). É importante

\footnotetext{
${ }^{3} \mathrm{O}$ número de canções selecionados nas duas línguas (15 em inglês americano e 15 no português do Brasil) foi considerado suficiente para os objetivos da pesquisa.
} 
destacar que as expressões metafóricas foram acomodadas não apenas nas metáforas conceituais THE HEART IS THE PERSON e EMOTIONAL DISTRESS IS PAIN INFLICTED TO THE HEART, mas também em outras, como veremos mais adiante.

Para a análise das metáforas encontradas no corpus do presente estudo, além de utilizarmos as metáforas conceituais reveladas por Divardin (2000), sempre que necessário usamos outros estudos que versam sobre o tema. Um exemplo é o estudo de Pérez (2008), também desenvolvido a partir de Modelos Cognitivos Idealizados (Idealized Cognitive Models), que é o modelo segundo o qual o processo de pensamento opera (Lakoff, 1987). Destaco que a análise das letras das canções selecionadas não usou de nenhum software ou aplicativo, a análise foi feita por meio da localização das metáforas nas letras, comparação e acomodação nas metáforas reveladas em particular no estudo de Divardin (2000).

O estudo de Pérez, intitulado A Cross-Cultural Analysis of the Heart Metaphor, analisa as conceitualizações da palavra coração em cinco línguas, a saber: francês, italiano, espanhol, inglês e alemão.

Uma vez que o estudo de Divardin (2000) trabalha com o inglês americano e o português do Brasil, assim como este, consideramos que ambos se complementam, enriquecem e atualizam os estudos sobre a importância do reconhecimento e uso das metáforas convencionais no dia a dia.

\section{METÁFORAS: ALGUNS CONCEITOS IMPORTANTES}

A compreensão do que são metáforas, quais os tipos de metáforas bem como uma breve descrição de como as metáforas já foram consideradas nos estudos linguísticos e como elas são entendidas atualmente é importante para o presente estudo.

As palavras que compõem o léxico de qualquer língua possuem um sentido literal, ou seja, o significado básico do vocábulo, e o significado metafórico, que “...é o emprego de uma palavra ou locução que ordinariamente designa determinada coisa para designar outra" (Bowles, 2005). Por exemplo, a palavra raiz no seu sentido literal pode ser usada para nos referirmos à raiz de uma planta, já no seu sentido metafórico ela pode ser usada quando nos referimos, por exemplo, à raiz de um problema ${ }^{4}$ (Collins Cobuild, 1995).

\footnotetext{
${ }^{4}$ Grifo do original.
} 
É importante destacar que a metáfora, conforme mencionado anteriormente, tem sido objeto de estudo desde os tempos de Aristóteles, e a sua definição acaba se delineando com as mudanças que ocorrem com o passar dos tempos, de modo que os conceitos e as formas de entendê-la acabam se complementando.

As metáforas foram tidas por muito tempo como sendo típicas apenas de textos literários, expressões usadas apenas para embelezar e/ou tornar a linguagem literária mais rebuscada. Com o passar do tempo, as metáforas passam a ser entendidas como expressões que estão presentes na fala cotidiana de todos os falantes, a despeito do nível de escolaridade. Apesar da existência de metáforas mais formais e outras mais informais, todo e qualquer falante sabe usá-las de acordo com os diferentes contextos.

As metáforas também já foram entendidas como comparações entre dois termos. Por exemplo, na sentença “Aquele lutador é forte como um touro", temos a comparação entre um lutador com as características de força de um touro. Esse tipo de comparação, conhecido como símile, não tem a adesão nem a unanimidade de alguns estudiosos, conforme afirma Bowles (2005).

Uma outra perspectiva de metáfora é a de substituição. De acordo com esse entendimento, a metáfora "funcionaria apenas como um substituto direto para a expressão literal que tem exatamente o mesmo significado" (Honeck, apud Bowles, 2005, p. 24). Um exemplo tido como de metáfora de substituição é "O navio risca o mar", em que riscar o mar substitui metaforicamente o verbo navegar.

Já a literatura mais recente sobre a metáfora vai além da dimensão linguística, pois entende as metáforas como "recursos conceituais para compreender ou criar a realidade ao invés de apenas descrevê-la" (Kovecses, apud Bowles, 2005, p. 25). Esta compreensão mais abrangente faz parte dos estudos sobre a metáfora de acordo com a perspectiva da linguística cognitiva, sendo Lakoff e Johnson os grandes expoentes desta vertente.

Richards (1936), o criador de uma terminologia específica para os estudos do tema, diz que a metáfora envolve a relação de dois termos, a saber teor e veículo. Bowles (2005) ilustra esta relação em "Minha cunhada é um verdadeiro anjo", em que minha cunhada é o objeto da referência metafórica, chamada de teor, e a locução um verdadeiro anjo, que é a metáfora propriamente dita, é o veículo.

Outro aspecto destacado por Bowles (2005) diz respeito às funções das metáforas. O autor menciona que o uso das metáforas vai além da mera substituição de uma expressão literal ou que as metáforas são simples alternativas ao uso literal, o que 
sugeriria "que a cada expressão metafórica cabe uma contraparte literal" (Bowles, 2005, p. 28).

Entre as funções das metáforas mencionadas por Bowles está a possibilidade de expressar de forma sucinta, econômica e compacta determinados tópicos. Essa função pode ser observada no exemplo de Danesi (apud Bowles, 2005; p. 28): "Meu amor por é como um buquê florescente de rosas". Ao usar a metáfora buquê de rosas, é dito em poucas palavras um grande número de ideias: de que o amor é delicado, perfumado e belo. Ou seja, a metáfora pode cumprir uma função de economia da língua.

Ainda de acordo a teoria proposta por Lakoff e Johsnon sobre a metáfora, ela é uma representação mental e, portanto, cognitiva, que existe na mente e atua no pensamento. Sob essa perspectiva, o acesso às metáforas conceituais é automático, ou seja, não é necessário esforço para compreendê-las, uma vez que a expressão metafórica aciona imediatamente a metáfora conceitual correspondente na mente do indivíduo (Sardinha, 2007: 32-33).

As metáforas conceituais são convencionais, o que explica por que muitas vezes elas não soam como metáforas quando as usamos. Um exemplo disso é a naturalidade com que entendemos expressões como "a gente se cruzou e resolveu seguir a vida juntos". Ou seja, no nosso sistema conceitual, uma relação amorosa vivida a dois é entendida como uma viagem.

Sardinha (2007) lembra ainda que as metáforas são culturais, ou seja, "refletem a ideologia e o modo de ver o mundo de um grupo de pessoas, construídos em determinada cultura". Vale destacar, no entanto, que muitas metáforas conceituais operam em diferentes línguas e culturas da mesma forma; por exemplo, a metáfora conceitual $\mathrm{O}$ AMOR É UMA VIAGEM possui manifestações linguísticas em várias línguas - inglês, espanhol, francês, alemão e italiano (Pérez, 2008).

Uma vez que experimentamos e conceituamos o mundo a partir de nossas experiências por meio do nosso corpo, não é de admirar que muitas das metáforas conceituais tenham o corpo humano como origem. O dicionário Collins Cobuild (1995) dedica um capítulo todo às metáforas com partes do corpo, entre as quais podemos citar a própria palavra corpo, a cabeça, a face, os olhos, o nariz, os dentes, a língua e o coração. Este último - coração - é o foco de interesse do presente trabalho.

Com relação à sua tipologia, as metáforas são classificadas em estruturais, ontológicas, orientacionais, de personificação e primárias. Exemplos de metáforas 
estruturais são DISCUSSÃO É GUERRA, AMOR É VIAGEM e TEMPO É DINHEIRO.

Neste tipo de metáfora temos um conceito estruturado metaforicamente em termos de outro. As metáforas ontológicas permitem que identifiquemos nossas experiências de forma racional, como, por exemplo, quando concebemos a inflação como uma entidade física, na metáfora INFLAÇÃO É UMA ENTIDADE, "somos capazes de nos referir a ela, identificar nela um aspecto em particular, percebê-la como causa e agir a respeito disso" (Moreira, 2011, p. 4).

Como o próprio nome sugere, as metáforas orientacionais

são as responsáveis por organizar todo um sistema de conceitos em relação a
um outro. Boa parte delas está relacionada com a questão da espacialidade -
spatial orientation. Orientações espaciais tais como para cima/para baixo,
dentro/fora, frente/trás, centro/periferia emergem pelo simples fato de os seres
humanos possuírem corpos naturalmente constituídos do jeito como são,
atuando em um ambiente físico em determinada cultura (Moreira, 2011, p. 3).

Exemplos de metáforas orientacionais são BOM É PARA CIMA e RUIM É PARA BAIXO ${ }^{5}$. É importante destacar que estes tipos de metáforas podem variar de acordo com as diferentes culturas.

Sardinha explica que personificação em termos de metáfora são as "metáforas ontológicas em que a entidade é especificada como sendo uma pessoa" (Sardinha, 2007, p. 35). O exemplo apresentado por Sardinha é UMA TEORIA É UMA PESSOA, que vai gerar expressões do tipo "a teoria diz que... “, “os fatos revelam que...”. As metáforas primárias ou básicas citadas por Sardinha (2007, p. 35) "são aquelas motivadas por aspectos físicos do corpo humano". Exemplos deste tipo de metáfora são AFEIÇÃO É CALOR, INTIMIDADE É PROXIMIDADE e MUDANÇA É MOVIMENTO.

Outra definição importante nos estudos sobre metáforas é o de metonímia. Segundo Kövecses (apud Farias, 2006: p. 93), “ a função principal da metonímia é prover acesso mental, cognitivo a entidade alvo que não está facilmente acessível.”. Em outras palavras, a metonímia é substituição de uma palavra por outra, quando entre ambas existe uma relação de proximidade de sentidos que permite essa troca. Por exemplo: "O estádio aplaudiu o jogador".

Após a apresentação dos principais conceitos relacionados aos estudos sobre metáforas conceituais apresentamos as metáforas conceituais reveladas com as palavras heart e coração que serviram de base para a análise do corpus deste trabalho.

\footnotetext{
${ }^{5}$ Reforçando que todas as metáforas são apresentadas em letras maiúsculas de acordo com a convenção nos estudos sobre metáforas (Lakoff e Johnson, 1980).
} 


\section{METÁfORAS CONCEITUAIS JÁ REVELAdAS COM A PALAVRA HEART E CORAÇÃO}

Como mencionado anteriormente, o presente estudo está baseado em grande parte no estudo de Divardin (2000), que, por sua vez, se apoia na linguística cognitiva e na teoria conceitual de Lakoff e Johnson (1980, 1987, 1993). Divardin revelou a partir de expressões metafóricas convencionais com as palavras heart em inglês americano e coração no português do Brasil 11 metáforas conceituais.

O quadro abaixo mostra a produtividade das metáforas com o respectivo número de exemplos. As metáforas conceituais em negrito (números 7 e 11) são as que mostraram maior produtividade e que serviram de inspiração para o presente artigo.

\begin{tabular}{|c|c|c|c|}
\hline & $\begin{array}{c}\text { Inglês } \\
\text { Americano }\end{array}$ & $\begin{array}{l}\text { Portugês do } \\
\text { Brasil }\end{array}$ & Total \\
\hline $\begin{array}{l}\text { 1. O CORAÇÃO É O } \\
\text { RECEPTÂCULO DAS } \\
\text { EMOÇÕES }\end{array}$ & 14 & 12 & 26 \\
\hline $\begin{array}{ll}2 . & \text { O CORAÇÃO É O } \\
\text { RECEPTÁCULO (MORADA) } \\
\text { PARA A PESSOA AMADA }\end{array}$ & 17 & 33 & 50 \\
\hline $\begin{array}{ll}\text { 3. } & \text { O CORAÇÃO É O } \\
\text { LUGAR/SEDE DA } \\
\text { CORAGEM }\end{array}$ & 30 & 11 & 41 \\
\hline $\begin{array}{l}\text { 4. O CORAÇÃO É UM OBJETO } \\
\text { VALIOSO }\end{array}$ & 15 & 17 & 32 \\
\hline $\begin{array}{ll}5 . & \text { A VERDADE ESTÁ NO } \\
& \text { CORAÇÃO }\end{array}$ & 22 & 21 & 43 \\
\hline $\begin{array}{ll}6 . & \text { O CORAÇÃO É O } \\
& \text { EPICENTRO DAS EMOÇÕES }\end{array}$ & 25 & 28 & 53 \\
\hline $\begin{array}{l}\text { 7. ANGÚSTIA EMOCIONAL } \\
\text { É DOR IMPOSTA AO } \\
\text { CORAÇÃO }\end{array}$ & 32 & 25 & 57 \\
\hline $\begin{array}{l}\text { 8. CORAÇÃO VERSUS } \\
\text { RAZÃO: OS ESPINHOS DE } \\
\text { UM DILEMA }\end{array}$ & 15 & 18 & 33 \\
\hline 9. O CORAÇÃO É O CENTRO & 23 & 14 & 37 \\
\hline $\begin{array}{l}\text { 10. O CORAÇÃO É O } \\
\text { LUGAR/SEDE DA } \\
\text { MEMÓRIA }\end{array}$ & 04 & 04 & 08 \\
\hline 11. O CORAÇÃO É A PESSOA & 41 & 35 & 76 \\
\hline Total & 238 & 218 & 456 \\
\hline
\end{tabular}

Quadro 1: Produtividade das metáforas conceituais reveladas por Divardin (2000) ${ }^{6}$

\footnotetext{
${ }^{6}$ O quadro de Divardin (2000) está em inglês e a tradução é de responsabilidade da autora.
} 
As metáforas conceituais O CORAÇÃO É A PESSOA e ANGÚSTIA EMOCIONAL É DOR IMPOSTA AO CORAÇÃO, foco do presente estudo, foram subdivididas por Divardin em 2 subgrupos.

A seguir apresentamos os excertos das letras das músicas que compõem o corpus do presente estudo e a análise que acomoda as metáforas em O CORAÇÃO É A PESSOA e ANGÚSTIA EMOCIONAL É DOR IMPOSTA AO CORAÇÃO ${ }^{7}$ e nas demais metáforas conceituais encontradas.

\section{ANÁLISE DAS METÁFORAS NAS CANÇÕES COUNTRY e SERTANEJA}

O estudo de Coimbra et al (2010) verificou a predominância de metáforas ontológicas e estruturais nas letras das canções de quatro duplas sertanejas. As autoras do estudo reforçam que, uma vez que as canções sertanejas falam de amor - conceito abstrato - e de atividades do dia a dia, o uso de metáforas era esperado, pois as canções refletem o cotidiano, e o uso das metáforas é fundamental para a compreensão dos conceitos abstratos.

Já este estudo analisou e acomodou as expressões metafóricas convencionais com as palavras heart e coração presentes nas letras de canções country e sertaneja mostrando que as expressões são produtivas nas duas línguas corroborando o estudo de Divardin (2000) e ampliando o trabalho de Coimbra et al (2010).

A seguir apresentamos a lista das 30 letras (15 em português e 15 em inglês) selecionadas conforme mencionado anteriormente, bem como a análise feita das expressões metafóricas encontradas com as palavras coração e heart, lembrando que a seleção foi feita a partir do título das canções.

1. Quem vê cara não vê coração - Paula Mattos

2. Coração Indisponível - Israel Novaes

3. Coração Cansou - Michel Teló

4. Professor do Coração - Conrado e Aleksandro

5. Coração Cigano - Gino e Geno

6. Galera Coração - Edson e Hudson

7. Coração Sangrado - Edson e Hudson

8. Louco Coração - Spártaco

9. Me Leva Pro Seu Coração - Santorine

10. Coração Partido - Hugo e Rafael

\footnotetext{
${ }^{7}$ As metáforas aparecem ao longo do texto de forma intercambiável, ora em inglês ora em português.
} 
11. Tem nada a ver - Te cuida coração - Jorge e Mateus

12. A voz do Coração - Marília Mendonça

13. Coração de Papel - César Menotti e Fabiano

14. Coração carreira solo - Thiago Brava

15. A dona do meu coração - Henrique e Juliano

As canções em inglês foram as seguintes:

1. Go ahead and break my heart - Shelton Blake

2. My heart is open - Keith Urban

3. Hey heartbreak - Jennifer Nettles

4. Better than my heart - Luke Bryan

5. Some hearts - Carrie Underwood

6. Open season on my heart - Tim McGraw

7. My foolish heart - Lorrie Morgan

8. Part of my heart - Bill Anderson

9. Heart to heart talk - Kitty Wells

10. Unbreakable heart - Jessica Andrews

11. Somewhere in my broken heart-Billy Dean

12. You can't make a heart love somebody - George Strait

13. If a broken heart could kill - Montgomery Gentry

14. My heart has a mind of its own - Reba McEntire

15. A room in my heart - Faith Hill

A análise do corpus selecionado para este estudo demonstrou que a maioria das expressões metafóricas encontrada nas letras das canções country (23 expressões metafóricas) e sertaneja (21 expressões metafóricas) acomoda-se nas metáforas conceituais mais produtivas reveladas no estudo de Divardin (2000). Como mencionado anteriormente, a metáfora O CORAÇÃO É A PESSOA ${ }^{8}$ foi a metáfora com maior número de ocorrências no estudo de Divardin, com 41 ocorrências no inglês americano e 35 no português do Brasil. E a metáfora ANGÚSTIA EMOCIONAL É DOR IMPOSTA AO CORAÇÃO teve 32 ocorrências no inglês americano e 25 ocorrências no português do Brasil. Vale destacar que o corpus de Divardin não incluía canções country e sertanejas, como é o caso do presente estudo.

As metáforas encontradas neste estudo e que não se acomodam nas duas metáforas mais produtivas reveladas por Divardin (2000) foram acomodadas em outras metáforas conceituais reveladas pela mesma autora (ver quadro 2) como veremos a seguir, quando se apresenta a análise das metáforas das canções feita individualmente.

\footnotetext{
${ }^{8}$ As metáforas reveladas por Divardin (2000) são apresentadas em português neste estudo, sendo a tradução de minha responsabilidade.
} 
O quadro abaixo apresenta o número de ocorrências das metáforas encontras nas 30 canções analisadas de acordo com as metáforas conceituais reveladas no estudo de Divardin (2000). As metáforas em negrito são as metáforas que apresentaram maior número de ocorrência.

\begin{tabular}{|c|c|c|c|}
\hline & $\begin{array}{l}\text { Português do } \\
\text { Brasil }\end{array}$ & $\begin{array}{c}\text { Inglês } \\
\text { Americano }\end{array}$ & Total \\
\hline O CORAÇÃO É A PESSOA & 10 & 2 & 12 \\
\hline $\begin{array}{l}\text { ANGÚSTIA EMOCIONAL É } \\
\text { DOR IMPOSTA AO } \\
\text { CORAĈ̃O }\end{array}$ & 7 & 8 & 15 \\
\hline $\begin{array}{l}\text { O CORAÇÃO É O } \\
\text { LUGAR/SEDE DA CORAGEM }\end{array}$ & - & 2 & 2 \\
\hline $\begin{array}{l}\text { FALTA DE ANGÚSTIA } \\
\text { EMOCIONAL É SOSSEGO AO } \\
\text { CORAÇÃO }\end{array}$ & - & 1 & 1 \\
\hline $\begin{array}{l}\text { A VERDADE ESTÁ NO } \\
\text { CORAÇÃO }\end{array}$ & 2 & 1 & 3 \\
\hline $\begin{array}{l}\text { O CORAÇÃO É O CENTRO } \\
\text { DAS EMOÇÕES }\end{array}$ & - & 1 & 1 \\
\hline $\begin{array}{l}\text { O CORAÇÃ̃ É O } \\
\text { RECEPTÁCULO DAS } \\
\text { EMOÇÕES }\end{array}$ & - & 2 & 2 \\
\hline $\begin{array}{l}\text { CORAÇÃO VERSUS RAZÃO: } \\
\text { OS ESPINHOS DE UM } \\
\text { DILEMA }\end{array}$ & 2 & 2 & 4 \\
\hline $\begin{array}{l}\text { O CORAÇÃO É O } \\
\text { RECEPTÂCULO (MORADA) } \\
\text { PARA A PESSOA AMADA }\end{array}$ & 6 & 1 & 7 \\
\hline Total & 21 & 23 & 46 \\
\hline
\end{tabular}

Quadro 2: Produtividade das metáforas com a palavra coração e heart nas canções country e sertanejas analisadas no estudo.

Na canção de Paula Mattos com o título Quem vê cara não vê coração ${ }^{9}$, destacase um exemplo da metáfora conceitual A VERDADE ESTÁ NO CORAÇÃO revelada no estudo de Divardin (2000). De acordo com a análise de Divardin (2000), a verdade é geralmente difícil de ser percebida e não é acessível diretamente, assim ela é concebida como estando escondida, neste caso no coração. Divardin (2000) acomoda a expressão metafórica quem vê cara não vê coração como um desdobramento da metáfora conceitual A VERDADE ESTÁ NO CORAÇÃO e AS APARÊNCIAS ENGANAM.

\footnotetext{
${ }^{9}$ É importante destacar que em alguns casos foram encontradas metáforas com a palavra coração apenas nos títulos das canções. Nos casos em que exemplos foram encontrados em outros trechos das letras estes também foram analisados.
} 
Na canção Coração Indisponível de Israel Novaes, encontramos 3 exemplos de metáforas com a palavra coração. A primeira no título pertence à metáfora conceitual $\mathrm{O}$ CORAÇÃO É O RECEPTÁCULO/MORADA PARA A PESSOA AMADA, em que pode-se entender o coração como o local onde guardamos, protegemos a pessoa amada. No título da música observamos que o coração está indisponível, ou seja, já existe uma ou mais pessoas morando no coração.

Ainda nesta canção, temos a metáfora “... Pensa num coração vagabundo..”, que é explicada a partir da metáfora O CORAÇÃO É A PESSOA, uma vez que o coração representa de forma figurativa os traços de personalidade e de caráter, como a beleza, a força, a indiferença e a fraqueza. Neste exemplo temos o caso de um coração, de uma pessoa com traços negativos de caráter.

O terceiro exemplo de metáfora encontrado nesta mesma canção é “... Meu coração é de pedra...", que também é acomodada na metáfora O CORAÇÃO É A PESSOA, instanciando um exemplo de traço de caráter duro ou insensível.

A canção de Michel Teló, com o título de Coração cansou, contém apenas esta metáfora que é repetida ao longo da canção e que também pode ser acomodada em $\mathrm{O}$ CORAÇÃO É A PESSOA quando entendermos que uma vez que o coração representa a pessoa e as características do mundo físico, ou seja, uma pessoa se cansa ao desempenhar atividades físicas ou de determinadas situações emocionais.

Na canção Professor do Coração da dupla Conrado e Aleksandro, temos 2 exemplos de metáfora. O primeiro no título e que é repetido algumas vezes ao longo da canção, e “ ... no amor que há em mim, no amor sem coração...”. No primeiro caso temos um exemplo da metáfora conceitual O CORAÇÃO É A PESSOA, à medida que entendemos que o coração representa a pessoa que ama e desta forma pode ser ensinada. No segundo caso temos um exemplo da metáfora O CORAÇÃO É O LUGAR/SEDE DA CORAGEM. Divardin (2000) destaca que o uso da palavra coração como equivalente para coragem no português do Brasil é um tanto quanto restrito e que há a predominância de palavras como entusiasmo, ânimo e fibra, que é o caso do trecho “... amor sem coração..”, ou seja, a pessoa está sem entusiasmo, sem ânimo.

A próxima canção analisada é a canção de Gino \& Geno intitulada Meu Coração é Cigano. Nesta canção temos 4 ocorrências com a palavra coração. No título, em que acomodamos a metáfora em O CORAÇÃO É A PESSOA, ou seja, mais um caso de personificação do coração. Outro exemplo presente na canção é “... o coração no sufoco, 
de amor quase louco...", que podemos entender novamente como um exemplo da metáfora ANGÚSTIA EMOCIONAL É DOR IMPOSTA AO CORAÇÃO.

A dupla Edson e Hudson canta a canção Galera Coração, na qual se pede que a plateia, o público ou seus ouvintes tenham ânimo, ou seja, os cantores usaram a palavra coração para substituir entusiasmo/coragem, pois O CORAÇÃO É O LUGAR/SEDE DA CORAGEM. Além do título, temos o trecho “... é tanta emoção que não cabe no meu coração..." em que observamos a metáfora O CORAÇÃO É O RECEPTÁCULO DAS EMOÇÕES, ou seja, há tanta emoção que o coração transborda.

Ainda da dupla Edson e Hudson, na canção Coração Sangrado, se observa, além do título, o trecho que diz “... coração sangrado, amassado, pisado, morrendo de amor..." Os exemplos são da metáfora ANGÚSTIA É DOR IMPOSTA AO CORAÇÃO, que traz à mente imagens de desintegração e fragmentação do coração.

O cantor Spártaco em sua canção Louco Coração traz vários exemplos com a palavra coração. Além do título, que representa um exemplo da metáfora conceitual $\mathrm{O}$ CORAÇÃO É A PESSOA, temos “O meu coração tá pedindo pra você voltar...”, “... Tá louco, coração? Calma coração! Agindo desse jeito tá perdendo a noção. Eu não quero te ver outra vez sofrer" e ainda “..Entenda coração, não teima, coração, Cansei de ver você se metendo em confusão..." em que se observam exemplos novamente de $\mathrm{O}$ CORAÇÃO É A PESSOA e ANGÚSTIA EMOCIONAL É DOR IMPOSTA AO CORAÇÃO - "eu não quero te ver outra vez sofrer".

Outra canção que compõe o corpus da pesquisa é a canção de Santorine. No título Me leva pro seu Coração, temos a metáfora $\mathrm{O}$ coração é o receptáculo das emoções, por isso "Me leva para o seu coração”, lugar onde a pessoa amada fica protegida. Outro exemplo na canção é “... então é certo que um coração pode sofrer...” que acomodamos na metáfora O CORAÇÃO É A PESSOA e ainda “... já não consigo entender esse meu coração...", também um exemplo de O CORAÇÃO É A PESSOA.

Já é possível constatar que a metáfora conceitual O CORAÇÃO É A PESSOA é bastante produtiva nas canções sertanejas.

Na canção Coração Partido da dupla Hugo e Rafael, a mesma metáfora do título é repetida algumas vezes ao longo da canção. Esta metáfora é um exemplo de ANGÚSTIA EMOCIONAL É DOR IMPOSTA AO CORAÇÃO, que mais uma vez invoca a imagem de desintegração e fragmentação do coração. 
Jorge e Mateus, na canção Tem nada a ver /te cuide coração, falam de um coração possivelmente machucado e que deve preservar suas emoções. Outros trechos da canção que reforçam a ideia de precaução - “ ... já cansei de avisar pro meu coração, pra ele tomar cuidado...”, “.. coração sai machucado...”, e “.. vai com calma coração, te cuida com essa paixão.." - são mostras das metáforas CORAÇÃO VERSUS RAZÃO e ANGÚSTIA EMOCIONAL É DOR IMPOSTA AO CORAÇÃO. Nos excertos podemos observar os conselhos dados para evitar mais dor e decepção a um coração que sofre.

A próxima canção é de Marília Mendonça, $A$ Voz do Coração, que além do título apresenta ainda “... resolvi seguir meu coração, ouvir só a voz dele e não dar mais bola pra razão". Nestes trechos temos o caso da metáfora conceitual revelada no estudo de Divardin (2000) O CORAÇÃO VERSUS RAZÃO. Nestes excertos vemos a personificação do coração, por isso “ $a$ voz do coração”, e podemos também observar a supremacia do coração em “... não dar mais bola pra razão”.

A dupla César Menotti e Fabiano canta Coração de Papel, que, além da metáfora presente no título que é repetida várias vezes ao longo da canção, apresenta o trecho “.. porque fazer sofrer um coração que só lhe quer...". No primeiro caso, temos a metáfora ANGÚSTIA EMOCIONAL É DOR IMPOSTA AO CORAÇÃO, em que ter um coração de papel é o mesmo que ter um coração sensível. Este tipo de metáfora é acomodada no desdobramento da metáfora O CORAÇÃO É A PESSOA, que mostra por meio da linguagem figurativa características do mundo físico (Divardin, 2000: p. 138). O trecho “... porque fazer sofrer um coração que só lhe quer...” é acomodado na metáfora ANGÚSTIA EMOCIONAL É DOR IMPOSTA AO CORAÇÃO.

Na canção de Thiago Brava, Coração Carreira Solo, temos no título a metáfora O CORAÇÃO É A PESSOA, que é reiterada no trecho “... meu coração vai seguir carreira solo..” e outra em “... passei uma vida tentando emplacar aquele caso de amor dentro do meu coração..." em que observamos a metáfora O CORAÇÃO É O RECEPTÁCULO DAS EMOÇÕES.

Na última canção em português analisada Dona do meu Coração, de Henrique e Juliano, temos o título repetido no trecho "... porque você não vê que eu te amo e que é você a dona do meu coração...” e “... vem viver o que sonhamos juntos pois sem ter você o meu coração pode parar ..." . No caso de "dona do meu coração” temos a metáfora $\mathrm{O}$ CORAÇÃO É O CENTRO DAS EMOÇÕES e, no segundo excerto, “... o meu coração pode parar...", observamos que o coração é entendido como a própria vida e que sem o 
amor da pessoa amada ele pode parar de bater, ou seja, mais uma vez a metáfora conceitual O CORAÇÃO É O CENTRO DAS EMOÇÕES.

A seguir apresentamos a análise das 23 expressões metafóricas com a palavra heart nas letras das canções country selecionadas para o estudo e finalizamos com o levantamento das metáforas conceituas mais produtivas encontradas no corpus.

$\mathrm{Na}$ letra da canção de Shelton Blake com o título Go ahead and break my heart (Vá em frente e quebre meu coração) ${ }^{10}$, temos a metáfora ANGÚSTIA EMOCIONAL É DOR IMPOSTA AO CORAÇÃO seguindo a ideia de que o coração pode ser desintegrado e fragmentado por alguém. Nesta canção a frase é repetida várias vezes.

O mesmo ocorre na canção de Keith Urban My heart is open (Meu coração está aberto/livre); no entanto aqui a expressão metafórica é acomodada na metáfora conceitual O CORAÇÃO É O RECEPTÁCULO (MORADA) PARA A PESSOA AMADA. A ideia transmitida é de que o coração está livre e pronto para amar e receber alguém. Quando falamos de amor romântico, entendemos que o coração só tem um lugar disponível e não temos nenhum controle sobre quem vai entrar no nosso coração, pois o amor romântico é irracional. Já quando falamos em outro tipo de amor, existem vários lugares em nossos corações e, diferentemente do amor romântico, neste caso temos o domínio de quem entra e de quem sai.

A terceira canção analisada em inglês é de Jennifer Nettles, com o título Hey heartbreak (Hei, coração machucado). Nesta canção temos "Hey heartbreak, give me your key, (Ei, coração machucado me dê sua chave), Hey heartbreak, don't come back (Ei, coração machucado não volte mais) e Hey heartbreak, I'm breakin' up with (Ei, coração machucado, eu estou terminando com você)", trechos acomodados na metáfora O CORAÇÃO É O RECEPTÁCULO (MORADA) PARA A PESSOA AMADA. Isso pode ser justificado quando entendermos que o coração está machucado e de certa forma fechado; assim, para que alguém entre nesse coração é necessário que a pessoa permita, ou seja, entregue a chave desse recipiente. Se o coração não estivesse machucado, ele estaria aberto e sujeito à irracionalidade, à imprevisibilidade, à falta de controle e à loucura inerente ao amor romântico.

Em Better than my heart (Melhor que meu coração) de Luke Bryan podemos observar nos excertos "These cigarette eyes are about to burn out, they are better than my heart" (Estes olhos de cigarro estão prestes a se apagar, ainda assim eles estão

\footnotetext{
${ }^{10}$ A tradução dos títulos e dos excertos das canções é de responsabilidade da autora.
} 
melhores que meu coração) e "The soles of my boots have walked their last mile, but they are still doing better, better than my heart" (As solas do meu sapato já caminharam tudo o que podiam, mas ainda assim estão melhores que meu coração) podemos observar o uso da metáfora O CORAÇÃO É A PESSOA. Mais uma vez temos um caso de personificação do coração ou ANGÚSTIA EMOCIONAL É DOR IMPOSTA AO CORAÇÃO, pois temos a ideia de que o coração está sofrendo.

Na canção de Carrie Underwood, Some Hearts (Alguns corações) há vários exemplos da metáfora FALTA DE ANGÚSTIA EMOCIONAL É SOSSEGO AO CORAÇÃO. Os excertos abaixo mostram isso:

\author{
Some hearts( alguns corações) \\ They just get all the right breaks (Eles simplesmente têm as batidas certas) \\ Some hearts have the stars on their side (Alguns corações têm as estrelas ao seu lado) \\ Some hearts, they just have it so easy (Para alguns corações é tão fácil) \\ Some hearts just get lucky sometimes (Alguns corações têm sorte às vezes)
}

Já o excerto Some hearts burn out (Alguns corações queimam) corrobora mais uma vez a metáfora ANGÚSTIA EMOCIONAL É DOR IMPOSTA AO CORAÇÃO. E na linha You're the last thing my heart expected (Você é a última coisa que meu coração esperava) temos novamente a metáfora O CORAÇÃO É RECEPTÁCULO (MORADA) DA PESSOA AMADA e a ideia de que não temos o controle sobre quem vai entrar em nossos corações.

Na canção com o título Open season my heart (Temporada aberto no meu coração) de Tim McGraw temos um exemplo da metáfora O CORAÇÃO É RECEPTÁCULO (MORADA) DA PESSOA AMADA. Mais uma vez, observamos o amor romântico e um coração vazio e livre para uma nova temporada de amor que não sabe quem vai entrar. Na mesma canção aparece ainda Here's turning heartaches into art (Aqui estão transformando dor em arte) em que a metáfora é acomodada em ANGÚSTIA EMOCIONAL É DOR IMPOSTA AO CORAÇÃO.

Lorrie Morgan em My foolish heart (Meu coração bobo) mostra mais um exemplo de O CORAÇÃO É A PESSOA, ou seja, nesta canção também o coração apresenta traços de caráter ou personalidade. Em outros dois trechos da mesma canção temos “... Beware my foolish heart..." (Cuidado meu coração bobo) exemplos da mesma metáfora que mostra como uma pessoa boba, inocente (coração) precisa ser cuidadoso. 
Em Part of my heart (Parte do meu coração) com o cantor country Bill Anderson, além do título, todos os demais trechos são acomodados na metáfora O CORAÇÃO É RECEPTÁCULO (MORADA) DA PESSOA AMADA. Assim podemos entender que parte do meu coração sempre terá espaço para a pessoa amada.

Kitty Wells em Heart to Heart Talk (Conversa de coração para coração) apresenta um exemplo da metáfora conceitual A VERDADE ESTÁ NO CORAÇÃO que está de acordo com a ideia de que o que está ou vem do coração é verdadeiro e sincero. Os outros dois trechos da mesma canção "Why don't you ask your heart ask it if we should part" (Por que você não pergunta ao seu coração se nós deveríamos romper) e "I need to tell my heart exactly where we stand " (I preciso dizer para o meu coração como está nossa relação) são expressões geradas a partir da metáfora A VERDADE ESTÁ NO CORAÇÃO.

Em Unbreakable Heart (Coração inquebrável) de Jessica Andrews podemos ver em diferentes trechos exemplos da mesma metáfora ANGÚSTIA EMOCIONAL É DOR IMPOSTA AO CORAÇÃO. Nos exemplos desta canção temos o coração representando mais uma vez as características de caráter e personalidade, em particular de uma pessoa forte e que não se deixa abater.

Já em Somewhere in my broken heart (Em algum lugar do meu coração partido) de Billy Dean, a mesma frase é repetida várias vezes. A metáfora neste exemplo novamente representa a desintegração, fragmentação e sofrimento e é acomodada em ANGÚSTIA EMOCIONAL É DOR IMPOSTA AO CORAÇÃO.

Na canção You can't make a heart love somebody (Você não pode fazer um coração amar alguém) de George Strait, temos mais uma vez a personificação do coração e, portanto, a metáfora conceitual CORAÇÃO VERSUS RAZÃO. Outros exemplos na mesma canção são: "I've begged and I've pleaded with my heart" (Eu implorei e confessei ao meu coração), "My heart's the only part of me That's not in love with you" (Meu coração é a única parte de mim que não está apaixonada por você) e "You can lead a heart to love But you can't make it fall (Você pode levar um coração até o amor, mas você não pode fazê-lo amar).

Em If a broken heart could kill (Se um coração partido pudesse matar) do cantor de música country Montgomery Gentry, a mesma frase é repetida várias vezes ao longo da música. Aqui mais uma vez temos um exemplo que é acomodado na metáfora 
conceitual ANGÚSTIA EMOCIONAL É DOR IMPOSTA AO CORAÇÃO. Nesta canção ao mesmo tempo entendemos que alguém está com o coração partido mas também é possível entender que o coração partido é uma personificação e por isso ele poderia matar. Assim temos a metáfora ANGÚSTIA EMOCIONAL É DOR IMPOSTA AO CORAÇÃO.

Já Reba McEntire em My heart has a mind of his own (Meu coração tem sua própria razão) podemos observar que, no título e em outros trechos que são repetidos ao longo da canção, como em "I told this heart of mine our love would never be" (Eu disse para o meu coração que nosso amor nunca aconteceria) e "I say I'll let you go but then my heart says no" (Eu digo que vou te deixar partir, mas meu coração diz não), a mesma metáfora CORAÇÃO VERSUS RAZÃO é apresentada para reforçar a ideia de que o coração é uma personificação e, portanto, tem sua própria forma de pensar e agir.

A última canção country analisada foi A room in my heart (Um lugar em meu coração) de Faith Hill em que podemos observar novamente a metáfora O CORAÇÃO É O RECEPTÁCULO (MORADA) PARA A PESSOA AMADA. No trecho " $M y$ heart was once just like a home" (Meu coração já foi apenas como uma casa) "With many rooms and open doors" (Com muitos cômodos e portas abertas) e "There's a room in my heart for you” (Há um lugar para você em meu coração), a metáfora fica muito clara. Como já mencionado, no coração só há um lugar para uma pessoa, uma vez que, no amor romântico, ter muitos lugares no coração significa que a pessoa amada está sendo traída. Já, no amor afeto, ter muitos lugares é bom sinal, como na expressão Em coração de mãe sempre cabe mais um.

A análise das canções em português do Brasil e em inglês americano demonstrou a produtividade das metáforas conceituais com as palavras coração e heart respectivamente. Vale lembrar que o objetivo inicial era verificar a produtividade de duas metáforas em particular, a saber, O CORAÇÃO É A PESSOA e ANGÚSTIA EMOCIONAL É DOR IMPOSTA AO CORAÇÃO, pois foram as mais produtivas no estudo de Divardin (2000). A hipótese era de que, por se tratar de canções românticas, essa produtividade poderia ser encontrada no corpus selecionado.

Como já mencionado, no estudo de Divardin (2000) a metáfora conceitual O CORAÇÃO É A PESSOA foi a mais produtiva com 35 manifestações no português do Brasil e 41 no inglês americano. A segunda metáfora mais produtiva naquele estudo foi 
ANGÚSTIA EMOCIONAL É DOR IMPOSTA AO CORAÇÃO com 25 ocorrências no português do Brasil e 32 no inglês americano.

No presente estudo, a análise das 30 canções selecionadas demonstrou novamente que a metáfora mais produtiva foi ANGÚSTIA EMOCIONAL É DOR IMPOSTA AO CORAÇÃO, com 7 ocorrências no português do Brasil e 8 no inglês americano. A segunda metáfora mais produtiva foi O CORAÇÃO É A PESSOA, com 10 exemplos no português do Brasil e 2 no inglês americano.

Assim, a hipótese inicial de que as metáforas O CORAÇÃO É A PESSOA e ANGÚSTIA EMOCIONAL É DOR IMPOSTA AO CORAÇÃO seriam as mais produtivas das metáforas reveladas por Divardin (2000) foi confirmada, uma vez que o corpus da presente pesquisa foi composto por canções sertanejas e country, que são estilos de música romântica e que tratam de acontecimentos do dia a dia.

A seguir apresentamos as considerações finais, as limitações deste estudo bem como sugestões para novas pesquisas.

\section{CONSIDERAÇÕES FINAIS}

Como mencionado no início deste artigo, o objetivo da pesquisa desenvolvida era verificar a produtividade de expressões metafóricas com as palavras coração e heart geradas a partir das metáforas conceituais CORAÇÃO É A PESSOA e ANGÚSTIA EMOCIONAL É DOR IMPOSTA AO CORAÇÃO, metáforas que foram reveladas por Divardin (2000) em um corpus bem mais abrangente que o da presente pesquisa. A hipótese de que as metáforas seriam produtivas em canções sertanejas e country foi confirmada, pois estes estilos musicais são românticos e falam de emoções como amor, dor, angústia, perda, sofrimento, entre outras emoções.

O presente estudo limitou-se ao universo das canções sertanejas no português do Brasil e country no inglês americano, portanto é interessante que novos estudos sejam desenvolvidos incluindo outras variantes do português e do inglês nos mais diversos contextos de comunicação, por exemplo na fala informal cotidiana e nas redes sociais.

É importante destacar a importância de estudos sobre metáforas a partir de uma perspectiva cognitiva, pois reforçam que o uso das metáforas não é mais um artifício típico de obras literárias, mas que, por meio delas, temos acesso ao sistema conceitual com o qual entendemos o mundo e falamos das experiências cotidianas. 
No presente estudo foi possível observar quantitativamente, por exemplo, que nos estilos country e sertaneja, canções tipicamente românticas, as expressões metafóricas mais usadas para falar do coração, do amor, das alegrias bem como das tristezas causadas e/ou infringidas ao coração, estão ligadas ao entendimento conceitual de coração como uma pessoa e que as dores emocionais são dores impostas ao coração.

O número de ocorrências nas duas línguas das expressões metafóricas convencionais acomodadas nas metáforas escolhidas para o estudo confirmam que elas estão presentes nos sistemas conceituais das duas comunidades linguísticas, inglês americano e português do Brasil. A diferença quantitativa de exemplos das metáforas $\mathrm{O}$ CORAÇÃO É A PESSOA e ANGÚSTIA EMOCIONAL É DOR IMPOSTA AO CORAÇÃO, não deve ser entendida como um aspecto negativo do estudo, uma vez que as expressões que não pertenciam à estas duas metáforas conceituais, foram acomodadas em outras, conforme pode ser observado no quadro 2Outro aspecto a ser lembrado é o grande número de pesquisas que têm demonstrado o papel e o valor das metáforas no ensino/aprendizagem não apenas de línguas maternas e estrangeiras, mas também no ensino de química (Sales e Silva, 2015), de matemática (Oliveira, 2005) e formação de professores (Bezerra et al, 2011), por exemplo.

Sales e Silva (2015) em seu estudo sobre a importância do uso de metáforas no ensino de conceitos e da linguagem química apontam:

... que muitas vezes a dificuldade na compreensão dos conteúdos pelos aprendizes deve-se ao fato da Química ser estudada de forma fragmentada, envolver conceitos abstratos e linguagem simbólica bastante específica. Por esse motivo, ratifica-se a importância para se usar as analogias e as metáforas no ensino de conceitos abstratos e novos..." (Sales e Silva, 2015, p. 368).

Com relação ao ensino de matemática e a contribuição do uso de metáforas no seu ensino, Oliveira (2005), afirma que:

A metáfora desencadeia um processo de associações imagéticas ou verbais, por analogia, que constitui um verdadeiro exercício do pensamento analógico e criativo. Tais associações exigem de um professor habilidade e conhecimento para serem trabalhadas de forma adequada." (Oliveira, 2005, p. 33)

Um trabalho que aponta a contribuição do uso de metáforas nos estudos sobre formação de professores é o de Bezerra et al (2011). No estudo, professores em formação traduziram seus entendimentos, por exemplo sobre aprendizagem dos professores em formação por meio de metáforas como: jogo de futebol, receita, escada e árvore. 
Os exemplos citados acima reforçam como por meio de metáforas temos acesso ao sistema conceitual com o qual entendemos e explicamos o mundo e como falamos de nossas experiências diárias.

\section{REFERÊNCIAS}

BEZERRA et al. (Formadores de) professores em formação: traduzindo ensino-aprendizagem de línguas em metáforas. $8^{\text {a }}$ Semana de Licenciatura: $\mathrm{O}$ professor como protagonista do processo de mudanças no contexto social. Instituto Federal de Educação, Ciência e Tecnologia de Goiás - Campus Jataí, 2011.

BORTONI-RICARDO, S. M. O professor pesquisador: introdução à pesquisa qualitativa. São Paulo: Parábola Editorial, 2008.

BOWLES, H. L. Metaphors of Fire and Ice. v.1, 2,3. Tese de Doutorado. Universidade de São Paulo,1995.

BOWLES, H. L. Arqueologia da Raiva e do Entusiasmo: uma abordagem lexical. Ponta Grossa: Editora UEPG, 2005.

COIMBRA, J. S. et al. As canções dizem mais: desvelando metáforas presentes nas músicas sertanejas. Cadernos do CNFL, vol. XIV, n. 2, t. 1, pp. 248-259, 2010.

BOWLES, H. L. Arqueologia da Raiva e do Entusiasmo: uma abordagem lexical. Ponta Grossa: Editora UEPG, 2005.

DANESI, M. The role of metaphor in cognition. Semiotica, v. 77, n. 4, pp. 521-531, 1989 apud BOWLES, H. L. Arqueologia da Raiva e do Entusiasmo: uma abordagem lexical. Ponta Grossa: Editora UEPG, 2005.

DIVARDIN, G. W. Unlocking the secrets of the heart:um estudo da representação da palavra coração no sistema conceitual das línguas inglesa e portuguesa através de expressões metafóricas convencionais. Dissertação de Mestrado. Universidade Federal do Paraná, 2000.

.Unlocking the secrets of the heart - a view of the representation of the word "heart" in the conceptual system of the English and Portuguese Languages. Publicatio UEPG - Ciências Humanas, C. Sociais Aplicadas, Linguística, Letras e Artes, v.9, n.1, pp: 73-82, 2001.

FARIAS, E. M. P. Quantidade é elevação vertical: metáfora ou metonímia? (Quantity is vertical elevation: metaphor or metonymy). Revista do GELNE, V. 8 , Nos. 1/2, pp. 87-95, 2006.

HONECK, R. P. Historical notes on figurative language. In: HONECK, R. P.; HOFFMAN, R. R. (Ed.). Cognition and figurative language. Hillsdale, NJ: Erlbaum, 
1980 apud BOWLES, H. L. Arqueologia da Raiva e do Entusiasmo: uma abordagem lexical. Ponta Grossa: Editora UEPG, 2005.

HOFFMAN, R.R. Recent research on metaphor. Semiotic Inquiry, n.3, pp.35-62, 1983.

KÖVECSES, Z. Metaphors of anger, pride and love: a lexical approach to the structure of concepts. Amsterdam: John Benjamins, 1986 apud BOWLES, H. L. Arqueologia da Raiva e do Entusiasmo: uma abordagem lexical. Ponta Grossa: Editora UEPG, 2005.

LAKOFF, G. \& JOHNSON, M. Metaphors we live by. University of Chicago Press: Chicago, 1980.

LAKOFF, G. Women, Fire, and Dangerous Things: What Categories Reveal about the Mind. Chicago: University of Chicago Press. 1987.

LIMA, D. Expressões Idiomáticas: aprenda inglês como os gringos aprendem. Ebook, 2009.

MOREIRA, R. de F. Alguns aspectos sobre as metáforas de Lakoff e Johnson. Resenha de LAKOFF, G.; JOHNSON, M. Metaphors we live by. Chicago/London: The University of Chicago Press, 1980. pp.3-34.

OLIVEIRA, E.F. Analogias e Metáforas como recursos didáticos para o ensino da matemática. Dissertação. CEFET. Belo Horizonte, 2005.

PÉREZ, R. G. A Cross-Cultural Analysis of Heart Metaphors. Revista Alicantina de Estudos Ingleses, n.2, pp. 25-56, 2008.

RICHARDS, I. A., The Philosophy of Rhetoric. Oxford: Oxford University Press, 1936.

SALES, L. B. V.; SILVA, A. C. B. O ensino da linguagem química nas escolas públicas da cidade de Gravatá. In: Anais do Encontro das ciências da linguagem aplicadas ao ensino, 6, Garanhuns. Anais... Recife: Pipa Comunicação, 2015.

SARDINHA, T. B. Metáfora. São Paulo: Parábola Editorial, 2007.

Searle, J. Metaphor In: ORTONY, A (ed): Metaphor and Thought.Cambridge: Cambridge University Press, 1979.

\author{
SÍTIOS DE BUSCA DE LETRAS DE CANÇÕES EM PORTUGUÊS E EM \\ INGLÊS \\ https://www.vagalume.com.br/ \\ http://www.azlyrics.com/ \\ http://www.metrolyrics.com/top100-country.html
}

